\title{
Entrevista con Eugenio Coseriu en Granada
}

\section{Nota preliminar}

La entrevista se realizó con la ocasión del doctorado honoris causa de la Universidad de Granada (1993), dentro del ciclo de conferencias El intelectual y su memoria de la Facultad de Filosofía y Letras por María Ángeles Pastor; esa se encuentra en YouTube. Fue transcrita y adaptada por los estudiantes del seminario Edición de manuscritos y cartas del archivo Eugenio Coseriu (otoño de 2020) que se organizó dentro del proyecto de investigación de la Universidad de Zúrich „Über den Strukturalismus hinaus“ - Briefe an Eugenio Coseriu und die Geschichte der Linguistik im 20. Jahrhundert (https://www.coseriu100.info): Isabella Bellotti, Édera Bieri, Laura Biron, Manuela Crivelli, Ester Diez Ramos, Andersen-Jinxuan Wu y Marija Nikolic.

E.C. = Eugenio Coseriu; C.M.L. = Cándida Martínez López; Á. P. = Ángeles Pastor

C.M.L.: Saludos de la Facultad de Filosofía y Letras. Hoy, para nuestra Facultad, es un gran día, porque tenemos con nosotros al profesor Coseriu, que va a ser entrevistado dentro del ciclo El intelectual y su memoria, una tradición ya en nuestra facultad que cuenta con muchos nombres ilustres. Hoy, lógicamente, su presencia aquí y su memoria que va a ser grabada va a servir para incrementar ese fondo que ya tiene la Facultad de Filosofía y Letras, que además se encuentra en la Filmoteca de Andalucía. Va a ser entrevistado por la profesora Ángeles Pastor. En nombre de la Facultad quiero darles a ambos las gracias por su participación en este acto.

Á.P.: Yo tengo que empezar diciendo que, por fin, se cumple uno de mis deseos más queridos — por supuesto tengo más_- es decir, ver sentado aquí, en el aula que ha recogido las voces de tantas personalidades, al gran maestro, don Eugenio Coseriu. He de señalar que no es la primera vez que don Eugenio visita Granada, está en Granada su saber. Es habitual en los cursos de verano de Almuñécar y también ha estado en esta facultad en otras ocasiones. Yo incluso recuerdo una ocasión en que lo tuve enfrente riñéndome durante la lectura de mi tesis doctoral. En ese deseo o sueño del que les he hablado, lo que no había pensado nunca es que fuera precisamente yo la que estuviera aquí sentada a su lado. Por este honor quiero darle las gracias al equipo de Canal de la Facultad de Filosofía y Letras, porque realmente son muchos los profesores y las profesoras de esta Universidad (y no solo de filología) los que debemos magisterio al doctor Coseriu. También somos muchos los que le profesamos gran admiración y otros tantos, entre los que me encuentro, que le tenemos mucho cariño.

Sin más rodeos, he de decir (como antes que yo lo han dicho muchos otros) que estamos ante el más grande de los lingüistas vivos. Así lo calificó mi maestro inmediato don Gregorio 
Salvador, a la par que se confesó alumno suyo, alumno de don Eugenio Coseriu, en la laudatio con motivo del nombramiento como doctor honoris causa del sabio rumano por la Universidad Complutense de Madrid. Las razones por las que a don Eugenio Coseriu se le llama el lingüista mayor son bien conocidas por todos los investigadores del lenguaje, a menos aquellos que tienen un mínimo de sentido común. Mañana, en su nombramiento como doctor honoris causa por esta Universidad, el doctor Mondéjar analizará los grandes méritos intelectuales que concurren en él. Por esta razón, yo no me voy a detener en este preámbulo en ellos; solo destacaré algunas notas en su mayor parte ya dichas, porque de don Eugenio Coseriu se ha dicho ya muchas cosas, mientras que de su teoría todavía falta mucho por decir.

Quiero destacar, por ejemplo, su solida formación, que siempre sigue cultivando. No hay día en que don Eugenio Coseriu no trabaje, aunque se acueste muy tarde, como en los cursos de Almuñécar. Ahí, había cualquier festejo y se hacían las tantas de la noche. Cuando llegaba a la portería, don Eugenio pedía que lo llamaran a las seis de la mañana, con gran sopor por nuestra parte. Quisiera destacar su ancho saber, su pensamiento clarificador que ilumina todas las parcelas del quehacer lingüístico, desde la historia hasta la ahora tan de moda lingüística aplicada, pero también la lógica del lenguaje dentro de la filosofía del lenguaje. Su honestidad científica sería otra nota que destacar, alejada de todo exhibicionismo original. Efectivamente, para mí y para tantos otros su pensamiento es el más profundo y el de mayor dimensión teórica. Quizás como una anécdota - pero que es significativa - quisiera leerles las palabras de un lingüista japonés, llamado Takashi Kamei, que dice así: "la lingüística de Coseriu es mucho más de lo que podemos apreciar ahora mismo en ella, porque va a ser ni más ni menos que la lingüística del siglo XXI".

Pero pasemos a la vida de este profundo y fecundo humanista. Quizás consigamos, no sé, desentrañar alguna clave que nos enseñe a ser un poquito como él —aunque yo creo que la inteligencia no es cosa que se pueda aprender-. Don Eugenio Coseriu, salvo períodos no muy largos, ha vivido en cuatro países. Vamos a viajar con él por estos cuatro países intentando ver cómo ha cimentado, a lo largo de su vida, esta enorme personalidad y saber. Empezamos con Rumanía. Don Eugenio Coseriu nace en Mihăileni — pueblecito de Besarabia — en 1921. Esta región de la lejana — pero tan próxima culturalmente — Rumanía, tras la guerra mundial pasará a formar parte de la Unión Soviética dentro de una nueva República Socialista de Moldavia, aunque sigue otra parte en Rumanía que se sigue llamando Moldavia, ¿no?

$$
\text { E.C.: Sí. }
$$


Á.P.: En nuestro apasionante viaje coseriano, esta es la primera parada, Rumanía. En Mihăileni Coseriu realizó sus estudios primarios, en Bălți, los secundarios. En Besarabia, por tanto, vivió hasta 1939, esto es, infancia, adolescencia y parte de su juventud. ¿Qué recuerdos tiene de esta época?

E.C.: Antes de hablar de los recuerdos, desearía responder a una duda suya, que surgió con respecto a la posibilidad o no de aprender la inteligencia. La inteligencia, por cierto, no se aprende, pero en cambio sí se aprende el trabajo; en muchas ocasiones el trabajo puede incluso remplazar a la inteligencia o estimularla y desarrollarla. Yo diría de la ciencia lo que Goethe dijo de la poesía, cuando le preguntaron cuánto había de inspiración en ella. Pues dijo que la poesía es el $1 \%$ de inspiración y el $99 \%$ de transpiración. Lo mismo, sí, se aplicaría a la lingüística y a cualquier otra ciencia: el trabajo tesonero y regular es en realidad lo más importante. Claro que es también importante poder tener maestros, tener guías y tener a quien te diga "esto no merece la pena leerlo", "concéntrate mejor en esto otro", después de haberte dejado cierto tiempo de experiencias para que te des un poco de cabeza de aquí y de allá, y para que aprendas que no todas las puertas se abren con facilidad. Acerca de esos recuerdos... Ante todo, yo viví como niño muy normal que soy, jugando con los demás niños y, claro, peleándonos por las cosas que se podían ganar entonces en los juegos infantiles, como, por ejemplo, los botones. Teníamos unos juegos en los que podíamos ganar botones y yo solía llegar por la noche a casa con un bolso lleno. Pero también me pasaba que tenía que cortar varios botones, incluso de las mantas, por ejemplo, de las camas, porque los había perdido todos. Pero quizás le interese más la formación cultural y orientada de esta época. Pues yo estudié, hice la escuela primaria en mi pueblo natal y tuve una gran suerte, además de haber tenido la suerte de haber tenido a mis padres, padres muy especiales en todo sentido...

\section{Á.P.: ¿En qué sentido especiales?}

E.C.: Enseguida volveré a ello. Decía que tuve la suerte de tener a un verdadero maestro en la escuela primaria, al que siempre recuerdo en todas las entrevistas con respecto a mi formación intelectual. Se llamaba Roman Mîndîcanu. Murió hace poco. En realidad, fue él que empezó a moldearme y a darme cierta orientación y confianza en mí mismo. Incluso exagerando quizás a veces; pero creo que hizo bien porque los buenos en general somos tímidos $\mathbf{y}$ bastantes inseguros de nosotros mismos. Y este maestro fue el que, en cierto sentido, me descubrió. En cuanto a mis padres, ellos ya tenían esta idea de la cultura y del desarrollo intelectual del hombre 
en general y más todavía, claro, de sus hijos. Por ejemplo, mi madre que no había hecho estudios y que solo tenía la escuela primaria siguió toda la vida leyendo, informándose y buscando. Ahora, después de la muerte de ella, mi hermana descubrió entre sus papeles una cantidad de notas enciclopédicas que hacía ella para sí misma. Así que encontró, por ejemplo, una descripción del Museo Británico y todo lo que contiene el Museo Británico. Ella no lo había visto nunca pero quería saberlo. Encontró un vocabulario de palabras difíciles y entonces explicaba para ella de vez en cuando podía: “Esta palabra no la entiendo. ¿Qué es esto?”

Á.P.: Y la buscaba.

E.C.: Y la buscaba, sí. Bien, mi padre, en cambio, sí que había hecho estudios superiores y siempre insistió en que nosotros también, es decir, mi hermana y yo hiciéramos estudios. Es algo que no se concebía en nuestra familia, por ejemplo, que no se fuera a la universidad y que no se hiciera carrera universitaria en este plano. Por eso digo: padres, en este sentido, muy especiales, han hecho grandes sacrificios. Y en el liceo como se llama allí —el colegio como lo llaman en España - la escuela después de la escuela primaria, que lo hice en la ciudad de Bălți, tuve también maestros excelentes y excepcionales en muchos sentidos. Así que en la simple acumulación de saber, por ejemplo, yo creo que he hecho más en el liceo que más tarde. Porque después, por ejemplo, en los exámenes universitarios de fin de carrera en Alemania, estando yo con otros profesores, colegas que examinaban, he advertido varias veces que las preguntas que hacían con respecto a la literatura francesa o a tal otra literatura, pues todas yo las habría podido contestar ya desde el liceo; todo esto ya estaba acumulado desde entonces por lo menos como saber.

Á.P.: Como saber.

E.C.: Y en lo personal, en cambio, he pasado por varios países; así, más o menos, he llegado a ser un ciudadano del mundo, en realidad yo soy siempre aquel niño moldavo de Mihăileni; volví allí el año pasado. Y entonces, he advertido de que soy un desarraigado y de que una parte de mí, de alguna manera, se me había quedado allí. Entonces, en mi pueblo estuve buscando todos los lugares de mi infancia y adolescencia. Y no encontré casi nada, todo había desaparecido: mi casa ya no estaba, el pozo que teníamos frente a la casa había desaparecido. Solo encontré de mis tiempos un nogal. Y este nogal todavía lo reconocí. Y vi que era mi nogal y solo lo toqué, lo acaricié y de algún modo el respondió. 
Á.P.: La vida en ese momento en Rumanía, ¿usted la recuerda como dura en el sentido de desarrollo?

E.C.: Yo la vida siempre la recuerdo como dura.

Á.P.: ¿Siempre?

E.C.: Siempre. No he tenido casi nunca momentos en mi vida en que podía decir: "Ay, iqué bien!, no tengo que pensar en el mañana." Porque o no tenía yo dinero, o estaba solo y lejos de mi familia, o nacían hijos y habría que darles de comer. Así, que en este sentido para mí la vida siempre ha sido difícil.

Á.P.: Bien, todavía en Rumanía comienza sus estudios universitarios en Iași. ¿Qué es lo que estudia allí? ¿Qué destacaría de la formación recibida? ¿Qué destacaría de su actitud hacia esa formación? ¿Y por qué solo permanece un año en Iași?

E.C.: Bien, en Iași yo estudié Letras, es decir, mis padres me mandaron para que me inscribiera en la Facultad de Medicina. Pero yo fui y me inscribí en la Facultad de Letras.

Á.P.: ¿Por qué?

E.C.: Porque deseaba ya estudiar Letras y me había orientado hacia las Letras y la Filosofía ya desde el liceo. Y aquí quizás una anécdota porque precisamente se trata de la memoria y del intelectual. Ya en la época del colegio, habré tenido yo unos quince años o dieciséis años quizás, pensaba yo en esto y era mi sueño: en algún momento llegar a enseñarles la ciencia a los alemanes.

Á.P.: ¿A los alemanes en concreto?

E.C.: Y entonces, tenía unos cuadernos en los cuales no escribía, sino que hacía nada más que los proyectos, los planes, etc., por ejemplo, Historia de las lenguas y de los pueblos de Europa por el prof. Eugenio Coseriu de la Universidad de Heidelberg. 
Á.P.: ¡Ya se dio el título a sí mismo!

E.C.: Y a veces ponía Marburgo.

Á.P.: Cambiaba.

E.C.: A veces incluso Tübingen.

Á.P.: ¿También?

E.C.: Quiero decir que ya me proponía desde entonces las dos cosas: la historia y la lengua, el lenguaje. Y me fascinaban desde aquel entonces y ya con esta idea precisamente de devolver a los alemanes lo que ellos me habían enseñado. Bien, y entonces, me inscribí en la Facultad de Letras y allí de nuevo tuve grandes maestros. Hice varias secciones al mismo tiempo. En toda la carrera teníamos entonces, creo que, veintidós exámenes. Yo pasé catorce de los veintidós el primer año. Entonces hice filología románica, por ejemplo, con prof. Găzdaru y eslavística con prof. Caraman, latín con prof. Marinescu, estética y crítica literaria con un gran crítico e historiador de la literatura, con prof. Călinescu, etc., es decir, con toda una serie de grandes maestros. Pero el año siguiente tuve que salir, no tuve, sino que lo decidí porque había pedido ya una beca.

Á.P.: ¿Salir de Rumanía?

E.C.: Sí, salir de Rumanía. Había pedido una beca para Italia del gobierno italiano y me la había dado. Yo me había quedado solo porque mi región la habían ocupado los rusos. Y mis padres, mi familia, se habían quedado allí. Y así que estaba yo en esta parte de Rumanía solo y, como decía antes, me sentía muy liado a mi terruño; al quedarme allí solo, me sentía casi como en un país extranjero, a pesar de que era el mismo país rumano, pero sin familia y en una región que yo conocía poco. Es como si de repente Andalucía perteneciera a otro país y un andaluz que siempre ha vivido en Andalucía tuviera que vivir en Logroño, por ejemplo. Y entonces, probablemente se sintiera un poco fuera. Entonces fui a Italia.

Á.P.: Antes de entrar en Italia, un poco para terminar el ciclo de Rumanía y, haciendo un inciso, diremos que Rumanía será el primer país que otorga el grado de doctor honoris causa 
curiosamente tres veces. Digo curiosamente, en las fechas y además cada doctorado honoris causa por cada región de Rumanía. El primero fue en 1971, pero los dos segundos fueron en 1992, cuando cambió el sistema político, es decir, que usted fue profeta en su tierra con un sistema y con otro. Es un caso un poco insólito, ¿no?

E. C.: Sí, en esta época, negra o roja de Rumanía, precisamente del 70-71, hubo un momento de apertura cultural, y como los intelectuales, claro, me conocían muy bien, en particular los lingüistas, pues consiguieron que se me otorgara el doctorado honoris causa, incluso en la capital, con todas las de la ley. En cambio, estos otros, los últimos, son como una especie de premio tardío por parte de otras universidades que en aquel momento o no se atrevieron o también, quizás, al revés, pensaron que con un doctorado de Ceaușescu ya era bastante.

Á. P.: Usted ya nos ha introducido en el segundo país, que es Italia, donde va en el año 1940. Primero va a Roma donde está del 40 al 44, después a Padua del 44 al 45 y luego a Milán del 45 al 50. Ya nos ha respondido realmente a la pregunta de por qué se marcha de Rumanía y por qué va a Italia. Sin embargo, las fechas que hemos indicado de la estancia del doctor Coseriu en Italia me obligan a hacerle una pregunta: ¿qué ambiente recuerda usted haber sentido en esta Italia de preguerra y de guerra? ¿Cómo lo vivió?

E. C.: Pues Italia ya estaba en guerra cuando yo llegué allí. Pero hay que distinguir dos cosas: primero, las universidades del país, y por otra parte la guerra italiana de otras guerras de otros pueblos. Los italianos, afortunadamente, como son en su gran mayoría muy inteligentes, pues no tienen ningún apego a la guerra, al contrario, y desprecian el heroísmo. Así que, en realidad la guerra en Italia no se vivía con entusiasmo guerrero, etc., sino como una especie de castigo de dios y "vamos a ver cuándo termina esta guerra maldita"; esta era la actitud normal en Italia. En cuanto a la universidad, pues se mantuvo, a pesar del régimen político, absolutamente independiente y mantuvo la objetividad científica en todos los aspectos. No penetró la ideología política del momento en las materias científicas. Es decir, que Historia y doctrina del fascismo era una asignatura que se enseñaba en todas las universidades, pero fuera de esto no había, por ejemplo, una estética fascista o una lingüística fascista. He de decir que ahí nos sentíamos totalmente libres. Y en cierto sentido, para un extranjero incluso esta situación de guerra era una situación favorable porque había muy pocos alumnos. A veces un gran profesor, académico, me daba clase a mí solo. Además, como la mayoría de los estudiantes varones 
estaban en el ejército, movilizados, los estudiantes extranjeros estaban favorecidos porque había una gran cantidad de muchachas a su disposición.

Á. P.: No sería a disposición, ¿no?

E. C.: No, no, no quiero decir que ellas estuvieran a disposición, pero digamos desde nuestro punto de vista, digamos había...

Á. P.: mucho dónde elegir.

E. C.: Sí, sí. Este es el aspecto práctico de la universidad, pero yo pienso que lo que más interesa para el intelectual y su memoria es la formación que he recibido en Italia. En muchos sentidos me he considerado y me sigo considerando, en parte por lo menos, perteneciente a la cultura italiana y en particular a la lingüística italiana porque Italia ha sido el país que me ha formado, en el sentido de encauzar mis aspiraciones científicas un poco vagas, genéricas y quizás demasiado amplias. Un país que me ha enseñado también el método crítico y a arreglármelas solo en la vida porque, claro, pronto se rompieron las relaciones incluso con Rumanía y yo me quedé en Italia. En parte la actividad ulterior se debe a la necesidad de seguir viviendo. Esto quiere decir que, por un lado, claro, los estudios de lingüística y de muchas lenguas en Roma y después de filosofía en Roma, Padua y en Milán...

Á. P.: Sí, hace el Doctorado de Letras por la universidad de Roma en el 44 ¿no? y después el de Filosofía por la universidad de Milán. ¿Y por qué dos doctorados?

E. C.: Pues... para empezar; después se pueden añadir otros. Bien, pues, entonces en Roma, me dediqué sobre todo a la Filología románica y eslava e hice también esta tesis doctoral sobre La influencia de la poesía épica medieval francesa sobre la poesía épica popular serbio-croata.

Á. P.: El título es largo.

E. C.: Sí, sí, el título es largo y la tesis también. Después, en cambio, ya había advertido yo que no se podía hacer teoría seria sin estudiar filosofía al mismo tiempo y entonces me dediqué en particular a la filosofía. Sobre todo, porque ya en mi época de Rumanía me había ocupado de estética y después en los años en que hacía Letras en Roma, también había seguido con la 
estética, así que decidí estudiar ya la estética dentro del ámbito de la filosofía. Tuve también bastante suerte con los maestros; en estilística tuve un gran maestro, Giovanni Maver e, indirectamente, en lingüística general, a Antonino Pagliaro y, después, en Milán para filosofía, en particular, a Antonio Banfi. Son en tal medida mis maestros que mucho más tarde dediqué un libro a la memoria de estos tres grandes maestros que he tenido en Italia. Por otra parte, la vida cotidiana, sobre todo después de la guerra, se había puesto muy dura. Yo me había casado, ya tenía una hija y tenía que trabajar. Entonces estaba de lector de rumano en la Universidad de Milán, pero se ganaba muy poco. No bastaba para vivir. Trabajaba de periodista todas las noches haciendo la parte de noticias del exterior y de día trabajaba en la enciclopedia Hoepli, donde teníamos de director a un profesor de gimnasia, que odiaba a los intelectuales. Entonces nos fuimos allí a buscar trabajo, primero yo y, después, otros jóvenes doctores, porque no bastaba lo que se ganaba en el periódico. Además de empezar a escribir las pocas cosas de lingüística allí, también había cometido cuentos.

Á.P.: Así por la mañana hacía una cosa, por la noche hacía otra y además escribía lingüística y además escribía cuentos. ¿Cuándo dormía?

E.C.: Dormía muy poco y muchas veces casi no dormía. Entonces escribía estos cuentos y hacía la crítica de arte porque se pagaban.

Á.P.: ¿No vuelve a escribir cuentos? ¿Ha escrito solo los cuentos de Italia?

E.C.: Solo hago un cuento chino. No, lo que quiero decir es que toda esta experiencia muy dura, por cierto, después, en la perspectiva histórica, se ve casi con gratitud porque se ha aprendido mucho en cada una de estas situaciones, en cada uno de estos ambientes. En el periódico, por ejemplo, se aprende a juntar las varias noticias, a ver las conexiones y a escribir en seguida la situación del día, es decir, a redactar con sentido y al mismo tiempo rápidamente. En la enciclopedia, pues, uno no ha hecho solo peso y medidas toda la vida, sino también filósofos, matemáticos incluso lingüistas y con eso se aprende muchísimo. También se había hecho una sociedad de lingüística en la Universidad de Milán, que hizo Vittore Pisani, el profesor de lingüística de entonces, que llegó a ser mi suegro. Entonces yo entré también en este centro y así empezó la orientación ya más hacia la lingüística. Contaré ahora una anécdota de la enciclopedia, que después puede cortarse si no la quieren incluir. En cierto momento, el hijo del dueño de la editorial llegó a hacer una especie de revisión de cómo se trabajaba y del 
trabajo mismo. Me llamó también a mí. En aquel tiempo yo estaba haciendo las voces de las biografías de matemáticos. Entonces él me mira y dice: "Ahora bien, doctor Coseriu, en su opinión, hay matemáticos de la historia. — ¿Matemáticos de la historia? No. ¿Qué quiere decir esto? - Sí, usted dice que los hay. ¿Dónde?, digo. - Aquí. A ver dígame. Aquí escribe usted así: «Cauchy, uno de los mayores matemáticos de la historia»”.

Á.P.: Matemáticos de la historia. Bien, Italia también le reconoció como Rumanía su labor investigadora concediéndole, posteriormente, el doctorado honoris causa por la Universidad de Boloña. Como el tiempo cada vez nos va premiando más y estamos en 1951, vamos a tener que ir un poquito más rápido. En Uruguay, es decir, el tercer país, continúa el viaje de este, como él mismo ha dicho, ciudadano del mundo. En 1951, se traslada a Uruguay, país al que me consta que tiene usted un especial cariño, puesto que adopta su nacionalidad y, de hecho, aún la conserva. Otra vez la misma pregunta que hemos hecho cada vez que hemos cambiado de país: ¿Por qué deja Italia y por qué Uruguay? Tendremos que ser más breves porque nos quedan muchos años.

E.C.: Es muy fácil. En este caso, la respuesta va a ser muy breve. Italia se deja por el hambre porque esta época, los años 50 y 51 fueron los peores de Italia después de la guerra. Estábamos todos jóvenes doctores buscando alguna salida de Italia. Entonces se publicaba en los periódicos que la Universidad del Witwatersrand en África del Sur estaba buscando profesores. Discutimos: “QQué vamos a hacer?” “Qué dices?” “Vamos a la África del Sur?” Otro día apareció también un aviso de la Universidad de Kabul en Afganistán. También buscaba profesores de cualquier cosa y pagaba muy bien. Nos preguntamos: “¿Vamos a Afganistán?” “QQué vamos a hacer?” Entonces conocí al cónsul de Uruguay en Milán, quien me preguntó qué quería hacer. Le dije: "Bueno, vamos a ver, ahora quieren profesores en África del Sur y en Kabul.” En la universidad, yo había hecho también persa y en Kabul se habla precisamente persa. Dice él: “¿Por qué al Afganistán, hombre? ¿Por qué no al Uruguay? Allí tenemos fundada la Facultad de Humanidades y necesitamos profesores." Entonces me fui al Uruguay y allí me quedé muy contento.

Á.P.: Durante once años en Uruguay.

E.C.: Sí, prácticamente doce años estuve allí. 
Á.P.: Bueno, es conocido que la mayor parte o al menos una considerable parte de su producción científica fue creada en Montevideo e incluso sus apuntes todavía no publicados en aquel momento. Más tarde sus notas le han servido para producciones que se publicaron al final. Es curioso que usted se vaya en 1951 a Montevideo y ya en 1952 publique Sistema, norma y habla, que modifica totalmente el paradigma saussuriano. Esa obra fundamental que seguimos trabajando y consultando, ¿la hace en un año?

E.C.: Yo todos los escritos, los escribo primero en la cabeza y los pienso a veces hasta en la formulación. Entonces ya tenía las ideas que allí aparecen en parte antes. En Milán, había escrito un pequeño ensayo sobre la lengua de un poeta rumano, Ion Barbu, donde había descubierto que lo creativo de Barbu quedaba dentro de la lengua a pesar de que las palabras, las construcciones, etc., no se encontraban en el diccionario porque no correspondían a la norma, sino que eran creaciones de acuerdo con el sistema de posibilidades. Claro que no tenía las ideas tan claras. Después se fueron aclarando y en realidad escribí el libro Sistema, norma y habla en exactamente diez días.

Á.P.: En estos once o casi doce años, Don Eugenio Coseriu publica además de Sistema, norma y habla, Sincronía, diacronía e historia, Sustancia y forma del contenido, es decir, todo el cuerpo doctrinal realmente al que tenemos que volver continuamente. Además, en ese tiempo está formando un departamento de humanidades porque cuando usted llegó a Montevideo prácticamente no había nada. ¿Cómo formó lo que incluso se ha llegado a llamar Escuela de Montevideo?

E.C.: En Italia, yo había hecho lo que se podía. Me había, sobre todo, dedicado a lecturas infinitas y después a este trabajo. En cambio, en Uruguay ya tenía esta posición en una época bastante buena. Además, es un país muy generoso en todo sentido porque me dió la posibilidad de trabajar. Entonces, dividí más o menos mi trabajo en tres secciones. Por un lado, lo que tenía que hacer para seguir viviendo. Y, además, en este tiempo aumentaba la familia, nacía otro hijo y entonces necesitaba otro curso. Entonces preguntaba a ver qué curso libre hay porque las cátedras se pagaban por curso. Entonces, decía: "Parece que estética. Muy bien, vamos a tomar estética. Parece que latín. Bien, latín”. Entonces llegué a dar hasta ocho cursos diferentes en el Instituto de profesores, es decir, Latín, Introducción a la lingüística, Filosofía del lenguaje, Estética, Historia de la lengua española, etc. Al mismo tiempo, todo esto tenía también una función formativa para mí mismo, porque uno enseñando aprende. Por otra parte, había que 
hacer lo que se podía allí. El país no tenía tradición en la lingüística ni tradición en las formalidades fuera de la formación autodidacta de varias personas. Además, no había bibliografía suficiente, faltaban las revistas. La colección de las revistas del siglo XIX no estaba. Por lo tanto, prácticamente no se podía hacer lingüística descriptiva o histórica. Se podía hacer la lingüística descriptiva solo sobre lo local, o bien se podía hacer lo que era posible sin mucha bibliografía vieja. Y lo que se podía hacer con la cabeza fue sobre todo la teoría si uno conoce los hechos más o menos. Entonces, desde el principio me dediqué a la teoría en este nivel de las ciencias. Y, desde el comienzo, entré en la discusión internacional porque no merece la pena plantear problemas que no tienen interés actual en el mundo científico y en la ciencia misma en cierta fase de su desarrollo. Por esto, me dediqué a esto. El problema que se presentaba en esta época era el de los esquemas de las dicotomías de Ferdinand de Saussure. Es decir, lengua y habla, sincronía y diacronía, etc. Entonces, se trataba de entrar a discutir precisamente estos problemas en el plano más alto posible. Por otra parte, había que hacer también lo que se podía, se debía y se quería para los alumnos. No se trataba de formar simplemente a los profesores de secundaria (los que salían de los estudios profesores), sino preparar y formar a los discípulos y a los investigadores. Por esto entonces, tanto para los alumnos mismos como para los investigadores, se realizó toda una actividad de manuales, una Introducción a la lingüística que se publicó entonces multiplicada de una manera más pobre. Salió después, mucho más tarde en México, y luego en Madrid; es de 1951, de mi primer año de Montevideo. Y entonces había que hacer textos. Hice una antología de textos de estética para los alumnos de estética, también hice una antología de textos para el seminario de Historia de la lengua empezando con el latín arcaico hasta El Cid y el Auto de los Reyes Magos. Después hice, además, una antología de textos para la clase del latín. Es decir, toda esta labor que había que hacer porque simplemente no había.

Á.P.: Usted me comentó una vez una cosa que me sorprendió mucho y que a mí me resulta muy curiosa. Dentro de esta formación de la escuela de Montevideo, ¿cómo captó a una serie de personas para que hicieran, por ejemplo, dialectología u otras...

E.C.: Este ha sido mi principio en Montevideo, pero más todavía después en Alemania, que si alguien desea trabajar, que trabaje primero en lo suyo. Es decir, en lo que más le interesa y donde más trabaja con gusto. Es decir, no le puedo pedir a alguien que le interesa, por ejemplo, lo concreto y el trabajo de campo que haga teoría. Y a quien le guste la estilística no le puedo pedir que haga dialectología. Solo puedo hacerlo mucho más tarde cuando él vea que también son necesarios otros enfoques, entonces sí. Pero, para conquistar a alguien, se tiene que 
conquistarlo con lo que le gusta, le interesa y le atrae. Entonces en lugar de decirle: "No, hay que esperar... Empiece con lo que le guste.” Entonces, yo le doy, los materiales que tengo sobre esto, si los tengo, la bibliografía, incluso las ideas que puede después desarrollar, ya que las ideas son uno de estos bienes que se dan y no se pierden sino uno se queda con ellas. Es decir, la gente que se ha acercado, en realidad no puedo decir que los haya formado yo, sino que se han formado alrededor de esta pequeña sociedad. Habíamos hecho un Círculo de lingüística. Habíamos organizado una biblioteca y sobre todo un fichero de los libros porque había pocos libros. Solo había los míos o los libros que se encontraban en varias bibliotecas públicas y privadas de Montevideo. Creo que esta fue una de las obras más importantes. Lo primero que hice al ver que no había suficientes libros en bibliotecas, pregunté en las bibliotecas públicas o privadas si tienen libros de lingüística. Y mandé a un grupo de estudiantes para ir a la biblioteca y mirar en el fichero lo que se encontraba. Pero también les mandé para ir a personas particulares, como abogados, profesores de la facultad de derecho o aficionados, que tenían libros de lingüística. Así se hizo un fichero casi digno de una ciudad universitaria europea con lo que encontramos en bibliotecas públicas y privadas; el fichero se hizo con siglas y se decía donde se encontraba tal obra. Entonces, cuando se le daba la bibliografía, el estudiante que tenía que hacer un trabajo, miraba ahí y veía que este libro se encontraba en tal parte. Si se encontraba en la biblioteca pública, no necesitaba ir a molestar al privado. Extrañamente, se encontraban muchísimos libros de lingüística en la biblioteca. Esto se debía a que, por casualidad, hubo un bibliotecario con un interés de aficionado por la lingüística en la biblioteca del Centro de Protección de Choferes o de chóferes, como dicen en España. Con respecto al Uruguay, cabe mencionar lo que se ha hecho ahí. En efecto, muchísimas obras se han empezado ahí y varias de ellas se han publicado. Muchas no se han publicado, pero las tengo en manuscrito o redacción bastante adelantada. Por ejemplo, una gran teoría del nombre propio. De esta, están escritas más o menos 560 páginas. También está la teoría del problema de la corrección idiomática que se hizo con Luis Juan Piccardo en la cual yo hice la parte de la teoría y él tenía que hacer la parte de la historia de los criterios de corrección de la gramática española. También hay otros trabajos, por ejemplo, sobre Vives que los tenía desde aquel entonces. Después en Alemania, en el momento que se presentaba algo urgente para mandar, una contribución a un tomo de homenaje o algo parecido, podía ver qué trabajo tenía ya realizado en Uruguay.

A.P.: Porque, además, en Uruguay también daba clases de lingüística española y es también cuando empieza a interesarse por el idioma, pero también por autores españoles como Luis Vives, etc. 


\section{E.C.: Sí.}

A.P.: Como Rumanía, también Uruguay le honró, o se honró, en 1980 concediéndole su segundo doctorado honoris causa. También, con esa Hispanoamérica tan querida y tan reivindicada por usted, se le han concedido otros tantos doctorados en Argentina, Chile, etc. Hablo conscientemente de la reivindicación del español de América porque es algo en lo que usted insiste en numerosas ocasiones. ¿En qué concreta esta reivindicación del español de América?

E.C.: Para decirlo en pocas palabras, lo que sostengo, más o menos, en este ensayo es el español de América y la unidad del idioma. Decir que el español de América amenaza la unidad del idioma, es como decir que el español de España amenaza la unidad del idioma porque se aleja del español de América. El español de América es simplemente español. Es una forma tan legítima como la del español de España que puede tener, en parte, otra norma de ejemplaridad. Pero, no es ni hijo del español, ni una derivación del español, sino que es simplemente español. Por lo tanto, no puede ni amenazar la unidad, ni hacerse otra cosa de lo que efectivamente es. Cuando se dice esto, se piensa en una ejemplaridad panhispánica. Es decir, que sea una ejemplaridad, norma ejemplar o lengua estándar en España y en los países americanos. Entonces, hay que pensar en la posibilidad de una ejemplaridad que tenga en cuenta el español de América que ya tiene un peso enorme en el mundo y, también, en la literatura, en la cultura en general, en lo idiomático y en el número de hablantes. En América hay ciudades que casi tienen la población de España. Lo digo con todo el cariño porque el cariño que le tengo a España no es menor que el cariño que le tengo a Hispanoamérica. Digo que los españoles de España tienen que convencerse de que Madrid es la capital de España, pero no es la capital del español.

A.P.: Pasamos, entonces, a Alemania: 1963 hasta la actualidad. Es el último país de su periplo vital científico. Ahí va a la prestigiosa Universidad de Tubinga. La pregunta de rigor que se ha hecho en los otros casos es, ¿por qué se marcha de Uruguay y por qué llega a Tubinga? ¿Quizás esté relacionado con el sueño que tenía al principio de Heidelberg?

E.C.: Sí, por eso me he adelantado en decirle eso. Me marché de Uruguay para tener más posibilidades de investigación y de formación de investigadores. En realidad, lo que había podido, realizar en Montevideo, en la medida de mis posibilidades, se había realizado. Ya había 
personas que investigaban, había una biblioteca y había revistas. Al llegar yo, no se recibía ni una sola revista de lingüística. Al salir yo de Montevideo, se recibían en el departamento de lingüística 72 revistas. Así que, prácticamente, ahí ya no se podía adelantar ni llegar a una expansión del trabajo de la teoría. Entonces, se me ofreció la oportunidad. De hecho, yo nunca he buscado cátedras, ni he pedido, ni me he presentado a ningún tipo de llamadas a aspiraciones porque no me gustaría que me rechazaran. Por eso, no me he presentado nunca. Entonces, estaba esperando tranquilo en Montevideo para ver cuando me llamarían. En 1963, pues, me llamaron prácticamente simultáneamente: tres universidades de Alemania, Bonn, Frankfurt y Tübingen; una universidad de Holanda, Leiden; y una de Estados Unidos, la de Seattle en el estado de Washington. Entonces, yo pude elegir y así no someterme a la humillación de presentarme a ver si me daban algo.

\section{A.P.: ¿Por qué escogió Tubinga?}

E.C.: Cogí Tubinga porque precisamente no era la capital. Bonn era entonces la capital. En ese sentido, la Universidad de Tubinga era más universitaria. Es decir, estaba más fuera del mundanal ruido y, también, más cercana a Italia. Entonces elegí Tübingen. Después de ahí, siguieron llamando de otras universidades: de nuevo Bonn, Viena, etc. Pero ya yo decidí quedarme en Tübingen.

A.P.: Desde el punto de vista científico, hemos dicho que el núcleo fundamental de toda su producción científica fue Uruguay. Le quería preguntar ¿en qué sentido en Alemania se modificó o se modifica la orientación de sus estudios que ya estaban tan definidos en Uruguay? Usted mismo ha dicho que cuando necesita publicar algo echa mano un poco de lo que tiene o de lo que ya ha hecho en Uruguay. ¿En qué sentido se modifica en este tiempo que pasa en Alemania hasta ahora?

E.C.: En realidad, cuando digo que todo estaba hecho en Uruguay, entiendo todo como en una semilla, todo como esbozado. Pero, había muchísimo que hacer y que todavía no se había hecho en Uruguay. Se trataba, ahora, de desarrollar algunas cosas de las que en Uruguay solo había algún intento o algún atisbo. Y había que desarrollar otras cosas nuevas incluso de las que en Uruguay se habían dado solo algunos ejemplos. Así, por ejemplo, toda la parte de semántica estructural, que es la parte que ha llegado a ser la más conocida, pues esta, se ha hecho en Alemania. La tipología, por ejemplo, la había empezado allí, pero de manera muy vaga, se ha 
hecho después en Alemania. Los varios estudios ya descriptivos, con otras posibilidades bibliográficas, por ejemplo, sobre el aspecto perifrástico en griego y sus continuaciones románicas, por ejemplo, o la coordinación latina románica, etc. con otra bibliografía, todo esto se ha podido hacer en Alemania. Y toda la aplicación, es decir, los estudios sobre teoría de la traducción, por ejemplo, que se trataba de aplicar una teoría ya, es basada en sus rasgos esenciales, pero no desarrollada y sobre todo no desarrollada en lo práctico. El lenguaje y la política, la política lingüística, todos estos aspectos, pues se han desarrollado en Alemania, y también varias cosas de las que tenía notas, de historia de la lingüística, por ejemplo, historia del proceder del lenguaje, etc. entonces las desarrollé después en Alemania. Y con otras posibilidades también de información y con otra posibilidad también de formación porque en Uruguay había una sola universidad, y, por lo tanto, no tenían come se dice salida las personas formadas. Mientras que en Alemania pues sí, he llegado a tener toda una serie de discípulos que ahora son profesores en varias universidades, etc. Y también trabajando con ellos, pues se presentaban cada vez nuevos problemas, y también se presentaban problemas de precisión, de especificación. Usted decía antes que yo escribo muy claro, etc., pero lo que queda claro para uno, no queda claro necesariamente para otros de manera que este contacto precisamente con los discípulos es solamente importante porque son los que dicen "¿qué quiere decir esto exactamente?" Yo sé lo que pienso, pero no sé si lo comunico exactamente. Y así también con estos desarrollos que decíamos, yo sabía ya entonces lo que diría sobre la traducción, pero lo he descrito después de 30 años.

Á.P.: Claro. Bueno, no nos podemos detener más en Alemania, por el tiempo, quizás destacar también su convivencia con muchas personalidades dentro de la universidad de Tubinga. Yo le decía como la mujer de Antonio Tovar me comentaba a su vez que en el tiempo que estuvieron allí era una universidad tremendamente viva, donde había enormes debates increíbles entre profesores con una personalidad muy hecha. ¿Quiere comentar algo brevemente de este ambiente?

E.C.: Sí, pues, sí, también en lo que caracteriza la universidad alemana primero es que por una razón o por otra, tiene esta autonomía tradicional, también en lo que concierne a los profesores que se llaman. Se pueden llamar profesores del mundo entero, de cualquier parte, con la única condición — si se trata del inglés, por ejemplo, incluso para tener la clase en inglés — pero si se trata de otra materia, la única condición es que se pueda dar la clase en alemán. Así es suerte que, por ejemplo, me habían llamado a mí, y después de unos años lo llamamos a don Antonio 
Tovar que había tenido dificultades en España y habría tenido que volver a los Estados Unidos, entonces dijimos “¿por qué no a Tübingen?” “Que es mucho mejor.” Y entonces, esto contribuye a esta pluralidad, este pluralismo, al mismo tiempo de ideas, de posiciones, de discusiones. Habíamos hecho, por ejemplo, también en seguida un círculo lingüístico donde teníamos a profesores de varias facultades y también profesores de filosofía, por ejemplo, o de lógica, etc. que cada uno podía contribuir en su sentido. Efectivamente sí, se había mantenido este espíritu de discusión y de interdisciplinaridad, muy libre con círculos filosóficos también donde de vez en cuando, por ejemplo, sobre ética de la ciencia, hablaba un profesor de mineralogía.

Á.P.: Hemos hablado de los cuatro países en los que ha estado Don Eugenio Coseriu, por supuesto ha pasado por muchas más universidades en períodos más cortos. Esto no habría sido posible sin su poliglotismo, es decir, sin la cantidad de lenguas, ¿cuántas lenguas habla don Eugenio?

E.C.: Es una pregunta que no se hace.

Á.P.: No se hace, ¿no?

E.C.: Y a un lingüista menos todavía porque el lingüista puede contestar, ninguna, porque nadie habla toda una lengua, no existe, nadie habla todo el español.

Á.P.: ¿En cuántas lenguas se comunica?

E.C.: Sí, tal vez se trata de comunicarse, entonces depende del nivel de la comunicación.

E.C.: Entonces, por ejemplo, si dice “¿de cuántas lenguas se ha ocupado, uno?”, entonces uno puede decir, "Bueno, más o menos, quizás 50, 60.” O algo así, que se ha ocupado, ha visto la estructura gramatical, y “¿en cuántas lenguas puede leer?”, “Pues, entonces puedo leer..., sí, 30,35 , etc. Y “¿en cuántas lenguas escribe?”

E.C.: Bueno, ya serán seis o siete, nada más.

Á.P.: Pero ¿escribe diferente si es prosa, si es poesía, si es científico? 
E.C.: La poesía lírica la escribo en rumano, la prosa literaria y la crítica de arte en italiano, los cuentos en italiano, y la ciencia en español.

Á.P.: Lo que he de agradecer es que la ciencia sea en español. Y ¿en qué lengua sueña?

E.C.: En la que corresponda.

Á.P.: Bien.

E.C.: Depende de la persona con que se sueña.

Á.P.: Y de las circunstancias. Bien, me hubiera gustado preguntarle también por, cómo ve el futuro del español, porque efectivamente a don Eugenio Coseriu le tenemos que agradecer, además de sus estudios en español, bueno, por supuesto toda su teoría lingüística, que es uno de los pocos científicos que le ha dado estatus de lengua científica al español, lo que no es muy normal. Creo que esto se lo tenemos que agradecer todos, absolutamente todos. Como el tiempo ya creo que lo hemos agotado, pues tendríamos que dejar para otra ocasión cuestiones tales como esa que le he planteada, cómo ve el futuro del español, cómo ve el futuro de la investigación lingüística en España, en Europa, en el mundo.

E.C.: Bueno, se puede contestar.

Á.P.: Pero muy rápidamente.

E.C.: El futuro del español lo veo muy bien con que se tome plena conciencia del hecho de que esta lengua pertenece al ser de cada uno de los hablantes hispánicos, y que constituye el fundamento de su ser histórico, y que, por lo tanto, no es simplemente un instrumento práctico, sino que es su forma cultural y lo que constituye la individualidad de esta cultura, y que entonces merece esta lengua el cuidado de todo hablante hispánico como lengua nacional de las varias naciones hispánicas. Y en este sentido sí, creo que el español tiene un gran porvenir; se ve, por ejemplo, en el hecho de que se estudia cada vez más en muchísimos países, en Corea, en Japón, se estudia mucho más de lo que se estudiaba antes, y más que otras lenguas que en cambio antes se estudiaban en primer término. En cuanto a los estudios lingüísticos, en España, en Europa y 
en otros países, pues estamos en momento actual, creo, en una época de crisis, pero de crisis de crecimiento, es decir, con gran diversidad de teoría, con intentos, varios, estamos en una época dionisíaca para llegar después a una época apolínea de clarificación y de nuevo equilibrio, etc. Quien ve ahora el panorama incluso en lo que se refiere a terminología, intentos de formalización, etc., pues, se asusta; y, los que ven la lingüística de fuera se asustan más todavía. Y algunos lingüistas también nos asustamos, pero, por otra parte, bien vista la lingüística desde dentro, se ve también como crisis de desarrollo y no de muerte.

Á.P.: Muy bien, pues, mi agradecimiento más sincero por habernos dejado un testimonio más de usted y de su obra. Con esta charla, con usted seguiremos estando horas y horas a través de sus obras. Espero que también usted esté mucho tiempo entre nosotros y que a partir de ahora el lugar que ocupa Granada en su corazón sea un poquito más grande.

E.C.: Muchas gracias. 